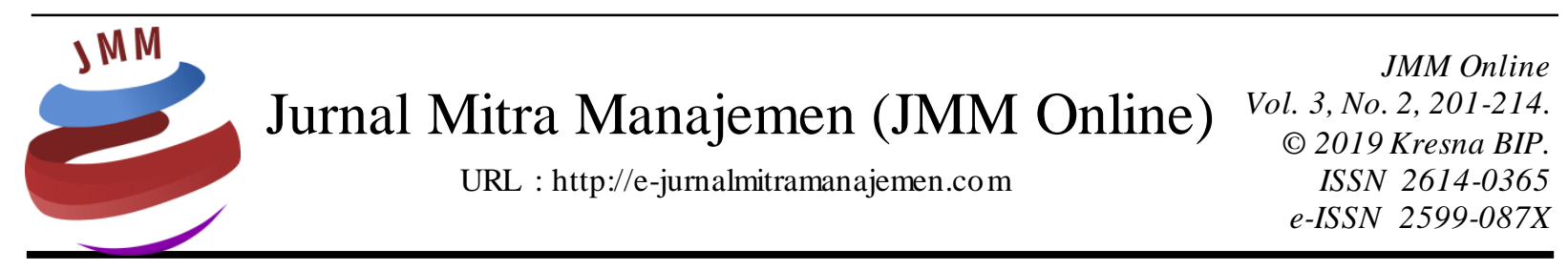

\title{
PENGGUNAAN TECHNOLOGY ACCEPTANCE MODEL (TAM) DALAM ANALISIS MINAT PERILAKU PENGGUNAAN E-MONEY PADA MAHASISWA UNIVERSITAS TELKOM
}

\author{
Wahyuni Nur Syahril 1), Brady Rikumahu ${ }^{2)}$ \\ Universitas Telkom
}

INFORMASI ARTIKEL

Dikirim : 12 Februari 2019

Revisi pertama : 19 Februari 2019

Diterima : 21 Februari 2019

Tersedia online : 04 Maret 2019

Kata Kunci : Technology Acceptance Model, Perceived Usefulness, Perceived Ease of Use, Behavioral Intention to Use E-Money

Email : wahyuninursyahril@gmail.com ${ }^{1)}$, bradyrikumahu@gmail.com ${ }^{2)}$
ABSTRAK 


\section{PENDAHULUAN \\ Latar Belakang}

Berkembangnya ilmu pengetahuan dan teknologi berhasil merubah pola hidup dan sistem pembayaran transaksi ekonomi di masyarakat. Meningkatnya mobilitas masyarakat mengakibatkan munculnya keinginan untuk melakukan kegiatan transaksi sehari-hari menjadi lebih mudah, efektif dan efisien namun tetap aman. Dewasa ini, kemajuan teknologi dalam sistem pembayaran secara bertahap mampu menggeser uang tunai sebagai alat pembayaran ke dalam bentuk pembayaran non-tunai yang lebih mudah, efektif, efisien dan aman.

Teknologi dan sistem informasi memiliki hubungan yang berkaitan dan terus berkembang, menyebabkan industri perbankan ikut melakukan inovasi-inovasi dalam sistem pembayarannya. Khususnya yang berkaitan dengan Financial Technology (FinTech) dalam rangka memenuhi kebutuhan masyarakat termasuk di bidang jasa sistem pembayaran, baik dari sisi instrumen, penyelenggara, mekanisme, maupun infrastruktur penyelenggaraan pemrosesan transaksi pembayaran. FinTech menghadirkan proses transaksi keuangan yang lebih praktis, aman, serta modern. Arner, Barberis, dan Buckley (2015) mengatakan bahwa FinTech dipandang sebagai pasar baru yang mengintegrasikan keuangan dan teknologi serta menggantikan struktur keuangan tradisional dengan proses berbasis teknologi baru. Salah satu hasil dari perkembangan FinTech yang bisa dirasakan saat ini oleh masyarakat yaitu adanya perubahan bentuk uang yang sangat pesat, baik uang kertas maupun uang logam yang mulai digantikan oleh electronic money atau biasa disebut dengan e-money.

Bank for International Settlement (BIS) dalam salah satu publikasinya pada bulan Oktober 1996 yang mendefinisikan uang elektronik sebagai "stored value or prepaid products in which a record of the funds or value available to a consumer is stored on an electronic device in the consumer's possession" atau "produk stored-value atau prepaid dimana sejumlah uang disimpan dalam suatu media elektronik yang dimiliki seseorang." (Hidayati, 2006:4). E-money memiliki beberapa kelebihan dibandingkan alat pembayaran elektronik yang lain, yaitu mengedepankan kecepatan, kemudahan, dan efisiensi dalam melakukan transaksi. E-money bertujuan untuk mengurangi tingkat pertumbuhan penggunaan uang tunai. Perkembangan e-money mampu menciptakan trendless cash society, yaitu suatu perilaku masyarakat yang menggunakan transaksi non-tunai dengan memanfaatkan kemudahan-kemudahan yang ditawarkan oleh alat-alat transaksi tersebut (Waspada, 2012:122).

E-money merupakan alat/instrumen pembayaran non-tunai yang relatif baru. Bank Indonesia baru pertama kali menerbitkan izin tentang e-money pada 2009 melalui Peraturan Bank Indonesia nomor 11/12/PBI/2009. Total dari penerbit e-money yang telah memperoleh izin edar dari Bank Indonesia hingga tahun 2018 adalah sebanyak 31 penerbit. Sejak penerbitan e-money pada tahun 2009 tersebut, Bank Indonesia telah mencatat jumlah e-money yang beredar (jumlah instrumen) serta jumlah transaksi $e$ money (volume dalam satuan transaksi dan nilai dalam juta rupiah) hingga tahun 2018 dalam tabel 1: 
Tabel 1. Jumlah Instrumen, Volume dan Nilai E-money

\begin{tabular}{|l|l|l|l|}
\hline Tahun & $\begin{array}{c}\text { Jumlah Instrumen } \\
\text { (dalam satuan) }\end{array}$ & $\begin{array}{c}\text { Volume (dalam } \\
\text { satuan transaksi) }\end{array}$ & $\begin{array}{c}\text { Nilai (dalam juta } \\
\text { rupiah) }\end{array}$ \\
\hline 2009 & 3.016 .272 & 2.037 .268 & 64.971 \\
\hline 2010 & 7.914 .018 & 2.898 .167 & 63.900 \\
\hline 2011 & 14.299 .726 & 4.669 .233 & 124.640 \\
\hline 2012 & 21.869 .946 & 10.260 .989 & 246.116 \\
\hline 2013 & 36.225 .373 & 12.442 .672 & 248.233 \\
\hline 2014 & 35.738 .233 & 26.154 .071 & 281.383 \\
\hline 2015 & 34.314 .795 & 41.606 .578 & 431.102 \\
\hline 2016 & 51.204 .580 & 79.228 .422 & 749.766 \\
\hline 2017 & 90.003 .848 & 163.301 .280 & 1.957 .290 \\
\hline 2018 & 167.205 .578 & 310.719 .605 & 5.886 .152 \\
\hline
\end{tabular}

Sumber: Bank Indonesia 2018, data yang telah diolah oleh penulis

Dari tabel 1 berdasarkan data dari Bank Indonesia mengenai jumlah instrumen, volume, dan nilai transaksi e-money dapat dilihat bahwa jumlah instrumen, volume, dan nilai e-money dari tahun 2009 sampai dengan 2018 rata-rata mengalami kenaikan di setiap tahunnya, meskipun ada penurunan tetapi tidak signifikan.

Berdasarkan latar belakang permasalahan dan beberapa referensi penelitian terdahulu mengenai permasalahan tersebut, peneliti tertarik untuk melakukan penelitian yang berkaitan dengan e-money dengan judul "Penggunaan Technology Acceptance Model (TAM) dalam Analisis Minat Perilaku Penggunaan E-Money pada Mahasiswa Universitas Telkom". Adapun unit analisis dalam penelitian ini adalah mahasiswa Universitas Telkom, mengingat saat ini jumlah instrumen, volume, serta nilai dari e-money semakin meningkat namun di lingkungan mahasiswa Universitas Telkom e-money belum diterapkan sebagai alat pembayaran secara keseluruhan dalam kegiatan bertransaksi sehari-hari, sehingga perlu dipastikan faktor apa saja yang dapat mempengaruhi minat terhadap penggunaan e-money pada mahasiswa Universitas Telkom.

Penelitian ini menggunakan teori Technology Acceptance Model (TAM) berdasarkan teori yang diungkapkan oleh Venkatesh dan Davis (2000) dalam Sayekti dan Putarta (2016) bahwa TAM merupakan sebuah konsep yang dianggap paling baik dalam menjelaskan perilaku user terhadap sistem teknologi informasi baru. TAM merupakan model yang dianggap paling tepat dalam menjelaskan bagaimana user menerima sebuah sistem.

Faktor TAM yang digunakan dalam penelitian ini yaitu perceived usefulness dan perceived ease of use sesuai dengan teori dari Davis (1989) yang menyatakan bahwa perceived usefulness dan perceived ease of use merupakan penentu dasar dari penerimaan pengguna. Penelitian ini kemudian menyarankan untuk menambahkan konstruk/variabel baru untuk mengetahui lebih rinci mengenai konstruk/variabel yang mempengaruhi keinginan penggunaan suatu teknologi.

Rick, Bohme, dan Moore (2015) memberikan bukti empiris bahwa penambahan variabel perceived risk dalam model TAM dapat diterapkan untuk menjelaskan penghindaran kejahatan pada layanan online. Dinyatakan bahwa penambahan variabel 
perceived risk pada model TAM juga dapat memperkuat saran sebelumnya untuk mempertimbangkan faktor negatif saat mempelajari mengenai penerimaan teknologi (technology acceptance).

Melalui modifikasi dan pengembangan teori $T A M$, dapat dipahami bahwa reaksi dan persepsi pengguna terhadap teknologi dapat mempengaruhi sikapnya dalam penerimaan penggunaan teknologi. Faktor yang dipilih untuk modifikasi dan pengembangan teori $T A M$ ada 3 yaitu faktor persepsi manfaat (perceived usefulness), persepsi kemudahan penggunaan (perceived ease of use), serta persepsi risiko (perceived risk) terhadap minat penggunaan (intention to use). Penelitian ini menggunakan 380 responden dengan metode kuantitatif dan teknik analisis data menggunakan teknik analisis deksriptif serta menggunakan analisis regresi linier berganda.

\section{Rumusan Masalah}

Berdasarkan rumusan masalah yang sudah diuraikan, peneliti ingin mengajukan pertanyaan meliputi:

1. Apakah persepsi manfaat (perceived usefulness) berpengaruh positif dan signifikan terhadap minat penggunaan (behavioral intention to use) e-money pada Mahasiswa Universitas Telkom?

2. Apakah persepsi kemudahan penggunaan (perceived ease of use) berpengaruh positif dan signifikan terhadap minat penggunaan (behavioral intention to use) $e$ money pada Mahasiswa Universitas Telkom?

3. Apakah persepsi risiko (perceived risk) berpengaruh positif dan signifikan terhadap minat penggunaan (behavioral intention to use) e-money pada Mahasiswa Universitas Telkom?

4. Dari faktor persepsi manfaat (perceived usefulness), persepsi kemudahan penggunaan (perceived ease of use), serta persepsi risiko (perceived risk) faktor manakah yang paling signifikan berpengaruh terhadap minat penggunaan (behavioral intention to use) e-money pada Mahasiswa Universitas Telkom?

\section{Tujuan Penelitian}

Berdasarkan pertanyaan penelitian yang ada, maka didapatkan tujuan penelitian sebagai berikut:

1. Mengetahui pengaruh persepsi manfaat (perceived usefulness) terhadap minat penggunaan (behavioral intention to use) e-money pada Mahasiswa Universitas Telkom.

2. Mengetahui pengaruh persepsi kemudahan penggunaan (perceived ease of use) terhadap minat penggunaan (behavioral intention to use) e-money pada Mahasiswa Universitas Telkom.

3. Mengetahui pengaruh persepsi risiko (perceived risk) terhadap minat penggunaan (behavioral intention to use) e-money pada Mahasiswa Universitas Telkom.

4. Mengetahui faktor yang paling signifikan dari persepsi manfaat (perceived usefulness), persepsi kemudahan penggunaan (perceived ease of use), serta persepsi risiko (perceived risk) terhadap minat penggunaan (behavioral intention to use) $e$ money pada Mahasiswa Universitas Telkom. 


\section{KAJIAN PUSTAKA}

Uang

Uang merupakan benda-benda yang disetujui oleh masyarakat sebagai alat perantara untuk mengadakan tukar menukar atau perdagangan. Terdapat kata sepakat diantara anggota-anggota masyarakat untuk menggunakan satu atau beberapa benda sebagai alat perantara dalam kegiatan tukar menukar (Sukirno, 2012:267).

\section{Electronic Money}

E-money adalah alat pembayaran yang memenuhi unsur-unsur yakni diterbitkan atas dasar nilai uang yang disetor terlebih dahulu kepada penerbit, nilai uang disimpan secara elektronik dalam suatu media server atau chip, digunakan sebagai alat pembayaran kepada pedagang yang bukan merupakan penerbit uang elektronik tersebut, dan nilai uang elektronik yang dikelola oleh penerbit bukan merupakan simpanan sebagaimana dimaksud dalam undang-undang yang mengatur mengenai perbankan (Bank Indonesia, 2014).

\section{Penerimaan Teknologi}

Penerimaan teknologi didefinisikan sebagai “as a user's willingness to employ technology for the tasks it is designed to support". Maksudnya bahwa penerimaan teknologi dapat didefinisikan sebagai kesediaan pengguna untuk menggunakan teknologi untuk mendukung tugas yang telah dirancang (Teo, 2011:1).

\section{Technology Acceptance Model (TAM)}

Model ini awalnya diusulkan oleh Davis dan telah menjadi model yang paling banyak digunakan untuk menjelaskan pengguna penerimaan teknologi baru. TAM dikembangkan dari Theory of Reasoned Action dan memberikan dasar untuk melacak bagaimana pengaruh variabel eksternal keyakinan, sikap dan niat untuk menggunakan teknologi baru (Wu et al., 2011). Model ini sudah digunakan untuk memprediksi penerimaan TI baru dan telah terbukti andal dalam menjelaskan perilaku penerimaan di beberapa bidang di Indonesia sistem informasi (Wu et al., 2011).

\section{Perceived Usefulness}

Menurut Yani et al. (2018), perceived usefulness merupakan sejauh mana seseorang percaya bahwa menggunakan suatu teknologi akan meningkatkan kinerja dari pekerjaannya.

\section{Perceived Ease of Use}

Perceived ease of use berarti keyakinan individu bahwa menggunakan sistem teknologi informasi tidak akan merepotkan atau membutuhkan usaha yang besar pada saat digunakan (free of effort) (Yani et al., 2018).

\section{Perceived Risk}

Menurut Oentario (2017), Persepsi risiko (perceived risk) didefinisikan sebagai prediksi konsumen tentang potensi ketidak-pastian dari transaksi online. Di masa lalu, Perceived Risk (PR) utamanya dianggap sebagai penipuan dan kualitas produk. 
Sekarang Perceived Risk (PR) mengacu pada tipe tertentu dari keuangan, kinerja produk, sosial, psikologis, fisik dan risiko waktu ketika konsumen melakukan transaksi online (Loanata, 2016).

\section{Behavioral Intention to Use}

$\mathrm{Gu}$ et al. (2009) menyatakan bahwa behavioral intention to use mencerminkan seseorang yang bersedia untuk mencoba dan bermotivasi untuk melakukan perilaku.

\section{METODE PENELITIAN}

\section{Tempat, waktu dan subjek penelitian}

Tempat penelitian ini dilakukan di Bandung. Waktu penelitian mulai dari bulan Juli 2018 sampai dengan Januari 2019. Subjek penelitian ini adalah mahasiswa Universitas Telkom.

\section{Karakteristik Penelitian}

Tabel 2. Karakteristik Penelitian

\begin{tabular}{|l|l|l|}
\hline No. & \multicolumn{1}{|c|}{ Karakteristik Penelitian } & \multicolumn{1}{c|}{ Jenis } \\
\hline 1. & Berdasarkan metode & Kuantitatif \\
\hline 2. & Berdasarkan tujuan & Deskriptif dan Kausal \\
\hline 3. & Berdasarkan tipe penyelidikan & Kausal \\
\hline 4. & Berdasarkan keterlibatan peneliti & Tidak Mengintervensi Data \\
\hline 5. & Berdasarkan unit analisis & Individu \\
\hline 6. & Berdasarkan setting penelitian & Non Contrived Setting \\
\hline 7. & Berdasarkan waktu pelaksanaan & Cross Section \\
\hline
\end{tabular}

Sumber : Indrawati, 2015

\section{Populasi dan Sampel}

Menurut Sugiyono (2018:148), populasi adalah wilayah generalisasi yang terdiri atas objek/subjek yang mempunyai kualitas dan karateristik tertentu yang diterapkan oleh peneliti untuk dipelajari dan kemudian ditarik kesimpulannya. Sedangkan menurut Indrawati (2015:164), populasi adalah keseluruhan kelompok orang, kejadian, benda-benda yang menarik peneliti untuk ditelaah. Populasi yang dipilih peneliti untuk ditelaah akan menjadi pembatas dari hasil penelitian yang diperoleh. Artinya penelitian hanya akan berlaku pada populasi yang dipilih. Seorang peneliti hanya dapat menyimpulkan hasil penelitiannya untuk populasi yang telah dipilihnya. Adapun populasi dalam penelitian ini adalah seluruh mahasiswa Universitas Telkom sebanyak 28.989 orang.

Menurut Indrawati (2015:164), sampel adalah anggota-anggota populasi yang terpilih untuk dilibatkan dalam penelitian, baik untuk dinikmati, diberi perlakuan, maupun diminta pendapat tentang yang sedang diteliti. Penelitian jarang menggambil seluruh anggota populasi untuk diteliti karena biasanya jumlah anggota dalam populasi sangat banyak sehingga apabila mengambil seluruh anggota populasi akan memerlukan dana, waktu, dan energi yang sangat banyak.

Teknik dalam pengambilan sampel biasa disebut dengan teknik sampling. Teknik sampling yang digunakan dalam penelitian ini adalah probability sampling 
dimana probability sampling adalah teknik pengambilan sampel yang memberikan peluang yang sama bagi setiap unsur (anggota) populasi untuk dipilih menjadi anggota sampel (Sugiyono, 2018:150 dan 151)

Jenis probability sampling yang digunakan adalah stratified random sampling. Teknik ini digunakan untuk menentukan jumlah sampel bila populasi yang dimiliki memiliki strata (Sugiyono, 2018:153). Perhitungan untuk mengetahui jumlah sampel yang digunakan pada setiap strata adalah sebagai berikut:

$\begin{array}{llll}\text { D3 } & =2709 / 28.989 \times 380 & & =40 \\ \text { S1 } & =25.475 / 28.989 \times 380 & & =334 \\ \text { S2 } & =450 \quad / 28.989 \times 380 & & =6\end{array}$

Untuk menghitung jumlah sampel dari populasi yang telah diketahui jumlahnya dengan menggunakan rumus dari Isaac dan Michael (Sugiyono, 2018:158), sebagai berikut:

Keterangan:

$$
s=\frac{\lambda^{2} \cdot N \cdot P \cdot Q}{d^{2}(N-1)+\lambda^{2} \cdot P \cdot Q}
$$

$\mathrm{s}=$ Jumlah sampel

$\lambda^{2}=$ Chi Kuadrat yang harganya tergantung derajat keabsahan dan tingkat kesalahan. Untuk derajat keabsahan 1 dan kesalahan 5\% harga Chi Kuadrat $=3,841$

$\mathrm{N}=$ Jumlah populasi

$\mathrm{p}=$ Peluang benar $50 \%=0,5$

$\mathrm{q}=$ Peluang salah $50 \%=0,5$

$\mathrm{d}=$ Perbedaan antara rata-rata sampel dengan rata-rata populasi. Perbedaan bias 0,01 ; 0,05 ; dan 0,10 .

Pada penelitian kali ini, jumlah populasi dari mahasiswa Universitas Telkom sebanyak 28.989 orang. Perbedaan rata-rata sampel dengan rata-rata populasi adalah sebesar 0,05 . Nilai $\lambda^{2}$ sebesar 3,841 dengan derajat keabsahan 1 dan tingkat kesalahan sebesar 5\%. Sedangkan probabilitas benar (diterima) atau salah (ditolak) masingmasing 0,5. Berdasarkan nilai-nilai yang telah ditentukan maka selanjutnya dimasukkan kedalam rumus Isaac dan Michael sebagai berikut:

$$
s=\frac{3,841 \cdot 28989 \cdot 0,5 \cdot 0,5}{0,05^{2}(28989-1)+3,841 \cdot 0,5 \cdot 0,5}=379,090
$$

Maka berdasarkan rumus Isaac dan Michael diatas, jumlah sampel pada penelitian ini adalah sebanyak 379,090 yang dibulatkan menjadi 380 sampel.

\section{Teknik Pengumpulan Data}

Penelitian ini menggunakan metode penelitian kuantitatif. Bila dilihat dari sumber datanya, maka pengumpulan data dapat menggunakan sumber primer dan sumber sekunder (Sugiyono, 2018:223). Menurut Sugiyono (2018:223), data primer adalah data yang pertama kali dicatat dan dikumpulkan oleh peneliti. Data primer dalam penelitian ini adalah kuesioner. Sedangkan data sekunder adalah data yang sudah tersedia dan dikumpulkan oleh pihak lain (Sanusi, 2011:104). Data Sekunder dalam penelitian ini antara lain berasal dari data website resmi, buku, jurnal-jurnal terdahulu, artikel online, dan informasi lainnya yang dianggap relevan dengan topik penelitian. 


\section{Teknik Analisis Data dan Pengujian Hipotesis}

Analisis deskriptif merupakan statistik yang digunakan untuk menganalisis data dengan cara mendeskripsikan atau menggambarkan data yang telah terkumpul sebagaimana adanya tanpa bermaksud membuat kesimpulan yang berlaku untuk umum atau generalis asi (Sugiyono, 2018:238).

Untuk mengubah data ordinal menjadi data berskala interval dapat dilakukan dengan MSI (Method Successive Interval). Prosedur statistik seperti regresi, kolerasi Pearson uji $\mathrm{t}$ dan lain sebagainya mengharuskan data berskala interval, sehingga data yang masih berskala ordinal harus diubah ke dalam bentuk interval karena data ordinal merupakan data kualitatif atau bukan angka sebenarnya.

Menurut Indrawati (2015:188) saat akan menggunakan regresi linier berganda, harus melakukan uji asumsi klasik terlebih dahulu sebelum melakukan pengujian hipotesis. Uji asumsi klasik terdiri dari uji normalitas, uji multikolinearitas dan uji heteroskedastisitas.

Uji normalitas data diperlukan karena hasil uji statistik (uji $\mathrm{T}$ atau uji $\mathrm{F}$ ) akan diinterprestasikan kedalam parameter dalam populasi karena data dalam populasi memiliki distribusi normal, maka data dalam sampel harus memiliki distribusi normal juga, sehingga dalam uji $\mathrm{T}$ dan uji $\mathrm{F}$ diasumsikan bahwa nilai residual mengikuti distribusi normal. Uji normalitas data memiliki tujuan untuk melihat apakah data terdistribusi secara normal atau tidak (Indrawatti, 2015:189).

Menurut Indrawati (2015:190) model multiple regresi yang baik seharusnya tidak terjadi korelasi yang tinggi diantara variabel-variabel independen karena akan menyebabkan nlai koefisien regresi berfluktuasi tinggi sehingga mengurangi keyakinan akan hasil pengujian, sehingga perlu dilakukannya pengujian terhadap data sampel apakah terjadi multikolinearitas atau tidak. Menurut Leahy (2000) dan Garson (2011) dalam Indrawati (2015:191) menyatakan bahwa jika nilai tolerance lebih besar dari 0.20 dan VIF kurang dari 4 menunjukkan tidak ada masalah multikolinearitas.

Uji heteroskedastisitas bertujuan untuk melihat apakah dalam model regresi terjadi ketidaksamaan variabel dari residual satu pengamatan ke pengamatan yang lain, jika varian dari residual satu pengamatan ke pengamatan lain tetap, maka disebut homoskedastisitas dan jika beberbeda disebut dengan heteroskedastisitas (Indrawati, 2015:191).

Hipotesis merupakan jawaban sementara terhadap rumusan masalah penelitian, dimana rumusan masalah penelitian telah dinyatakan dalam bentuk kalimat pertanyaan. Dikatakan sementara karena jawaban yang diberikan baru didasarkan pada teori yang relevan, belum didasarkan pada fakta-fakta empiris yang diperoleh melalui pengumpulan data. Jadi, hipotesis juga dapat dinyatakan sebagai jawaban teoritis terhadap rumusan masalah penelitian, belum jawaban yang empirik (Sugiyono, 2018:134). Pengujian hipotesis ini sendiri terdiri dari tifa tahap yaitu uji $F$, uji $t$, dan koefisien determinasi.

Menurut Sujarweni (2015) uji F merupakan pengujian signifikansi persamaan yang digunakan untuk mengetahui seberapa besar pengaruh variabel bebas (X1, X2, X3) secara bersama-sama terhadap variabel tidak bebas (Y). 
Menurut Sujarweni (2015), uji t merupakan pengujian koefisien regresi parsial individual yang digunakan untuk mengetahui apakah variabel (Xi) secara individual mempengaruhi variabel dependen (Y).

Indrawati (2015) berpendapat bahwa koefisien determinasi merupakan nilai yang digunakan untuk mengetahui seberapa besar dependen dapat diterangkan atau dijelaskan dengan menggunakan variabel independen.

\section{HASIL PENELITIAN DAN PEMBAHASAN}

\section{Uji Analisis Deskriptif dan Aspek Demografi}

Dilihat data yang telah diperoleh dan diolah dari 380 responden mahasiswa Universitas Telkom yang sudah menggunakan e-money, berdasarkan jenis kelamin terdapat $51 \%$ atau sebanyak 193 responden berjenis kelamin wanita dan $49 \%$ atau sebanyak 187 responden berjenis kelamin pria. Berdasarkan usia, terdapat responden dengan usia kurang dari 20 tahun yaitu sebesar $21 \%$ atau sebanyak 80 orang, usia dari 21 tahun sampai dengan 25 tahun yaitu sebesar $73 \%$ atau sebanyak 278 orang, usia dari 26 tahun sampai dengan 30 tahun yaitu sebesar 5\% atau sebanyak 19 orang, dan usia lebih dari 30 tahun yaitu sebesar $1 \%$ atau sebanyak 3 orang. Berdasarkan pendidikan, tingkat pendidikan D3 terdapat sebesar $11 \%$ atau sebanyak 40 orang, tingkat pendidikan S1 sebesar $88 \%$ atau sebanyak 334 orang, dan tingkat pendidikan S2 sebesar $1 \%$ atau sebanyak 6 orang. Dan berdasarkan fakultas, terdapat $56 \%$ atau sebanyak 215 orang untuk ekonomi dan bisnis, komunikasi dan bisnis memiliki tingkat persentase sebesar $13 \%$ atau sebayak 49 orang, industri kreatif memiliki tingkat persentase sebesar $11 \%$ atau sebanyak 41 orang, teknik informatika memiliki tingkat persentase $6 \%$ atau sebanyak 22 orang, teknik elektro memiliki tingkat persentase $6 \%$ atau sebanyak 22 orang, rekayasa industri memiliki tingkat persentase $3 \%$ atau sebanyak 12 orang, dan ilmu terapan memiliki tingkat persentase 5\% atau sebanyak 19 orang.

\section{Uji Normalitas}

Tabel 3. Hasil Uji Kolmogorov-Smirnov

\begin{tabular}{|c|c|c|}
\hline $\begin{array}{c}\text { One-Sampel Kolmogorov- } \\
\text { Smimov Test }\end{array}$ & Asymp. Sig & Keterangan \\
\hline 1,091 & 0,185 & Data berdistribusi normal \\
\hline
\end{tabular}

Sumber: Data yang telah diolah oleh penulis, 2018

Berdasarkan tabel 3 dapat disimpulkan bahwa data terdistribusi normal karena nilai signifikansi data terdistribusi secara normal yaitu 0.185 yang lebih besar dari 0.05 .

\section{Uji Multikolinearitas}

Tabel 4. Hasil Uji Multikolinieritas

\begin{tabular}{|l|l|l|l|}
\hline \multirow{2}{*}{ Model } & \multicolumn{2}{|c|}{ Collinearity Statistics } & \multirow{2}{*}{ Keterangan } \\
\cline { 2 - 3 } & Tolerance & VIF & \\
\hline Perceived Usefulness & 0,543 & 1,841 & Tidak terjadi multikolinieritas \\
\hline Perceived Ease of Use & 0,406 & 2,461 & Tidak terjadi multikolinieritas \\
\hline Perceived Risk & 0,454 & 2,200 & Tidak terjadi multikolinieritas \\
\hline
\end{tabular}

Sumber: Data yang telah diolah oleh penulis, 2018 
Tabel 4 menunjukkan nilai tolerance pada seluruh variabel independen lebih besar dari 0,20 dan nilai VIF seluruh variabel independen kurang dari empat. Dapat disimpulkan bahwa pada penelitian ini tidak terjadi multikolinieritas terhadap data yang diuji.

\section{Uji Heteroskedastisitas}

Tabel 5. Hasil Uji Glesjer

\begin{tabular}{|l|l|l|}
\hline Model & Sig. & Keterangan \\
\hline Perceived Usefulness & 0,100 & Tidak terjadi heteroskedastisitas \\
\hline Perceived Ease od Use & 0,069 & Tidak terjadi heteroskedastisitas \\
\hline Perceived Risk & 0,215 & Tidak terjadi heteroskedastisitas \\
\hline
\end{tabular}

Sumber: Data yang telah diolah oleh penulis, 2018

Tabel 5 menunjukkan nilai signifikansi seluruh variabel independen memiliki nilai lebih besar dari 0,05. Dapat disimpulkan bahwa variabel perceived usefulness, perceived ease of use, dan perceived risk terbebas dari heteroskedastisitas.

\section{Uji Analisis Regresi Linier Berganda}

Hasil perhitungan regresi linier berganda menggunakan aplikasi SPSS versi 21 dengan data yang terlebih dahulu telah diubah dari bentuk ordinal menjadi interval menggunakan MSI sebagai berikut:

Tabel 6. Koefisien Regresi

\begin{tabular}{|l|l|}
\hline Model & B \\
\hline Perceived Usefulness & 0,428 \\
\hline Perceived Ease of Use & 0,230 \\
\hline Perceived Risk & 0,355 \\
\hline
\end{tabular}

Sumber: Data yang telah diolah oleh penulis, 2018

Nilai konstata (a) yang diperoleh adalah $-0,337$ dan berdasarkan tabel 6 menunjukkan nilai koefisien regresi perceived usefulness $\left(b_{1}\right)$ adalah sebesar 0,428 , nilai koefisien regresi perceived ease of use $\left(b_{2}\right)$ adalah sebesar 0,230 , dan nilai koefisien regresi perceived risk $\left(b_{3}\right)$ adalah sebesar 0,355 . Sehingga persamaan regresi yang diperoleh ialah:

$$
Y=(-0,337)+0,428 X_{1}+0,230 X_{2}+0,355 X_{3}
$$

Dari hasil uji regresi berganda dapat disimpulkan bahwa variabel perceived usefulness berpengaruh lebih besar terhadap behavioral intention to use dibandingkan dengan variabel lainnya. Meskipun begitu perceived ease of use dan perceived risk juga berpengaruh positif terhadap behavioral intention to use.

\section{Pengujian Hipotesis Secara Simultan (Uji F)}

\section{Tabel 7. Hasil Uji F}

\begin{tabular}{|l|l|l|}
\hline & F Hitung & Sig \\
\hline F & 307,017 & 0,000 \\
\hline
\end{tabular}

Sumber: Data yang telah diolah oleh penulis, 2018

Dengan nilai df $1=3$ (jumlah variabel independen) dan df $2=377$ (jumlah responden - jumlah variabel independen), maka nilai $F$ tabel yang diperoleh ialah 
sebesar 2,40. Tabel 7 menunjukkan nilai $\mathrm{F}$ hitung sebesar 307,017 dan nilai sig sebesar 0,000. Dengan nilai $F$ hitung $(307,017)>F$ tabel $(2,40)$ dan nilai signifikansi $0,000<$ 0,05, maka Ho ditolak dan Ha diterima, yang menunjukkan bahwa perceived usedulness, perceived ease of use, dan perceived risk memiliki pengaruh positif dan signifikan secara simultan terhadap behavioral intention to use e-money.

\section{Pengujian Hipotesis Secara Parsial (Uji T)}

\section{Tabel 8. Hasil Uji t}

\begin{tabular}{|l|l|l|}
\hline Model & T Hitung & Sig \\
\hline Perceived Usefulness & 10,612 & 0,000 \\
\hline Perceived Ease of Use & 4,877 & 0,000 \\
\hline Perceived Risk & 8,474 & 0,000 \\
\hline
\end{tabular}

Sumber: Data yang telah diolah oleh penulis, 2018

Dengan nilai df $=376$ (jumlah responden - jumlah variabel independen -1 ) dan nilai $\alpha$ sebesar $5 \%=0,025(0,05: 2)$, nilai t tabel yang diperoleh ialah sebesar 1,968 . Tabel 4.6 menunjukkan t hitung dari variabel perceived usefulness terhadap behavioral intention to use sebesar 10,612 dan nilai sig sebesar 0,000. Dengan nilai t hitung $(10,612)>\mathrm{t}$ tabel $(1,968)$ dan nilai signifikansi $0,000<0,005$, maka Ho ditolak dan Ha diterima. Artinya, secara parsial perceived usefulness memiliki pengaruh positif dan signifikan paling besar terhadap behavioral intention to use e-money. t hitung dari variabel perceived ease of use terhadap behavioral intention to use sebesar 4,877 dan nilai sig sebesar 0,000 . Dengan nilai $t$ hitung $(4,877)>t$ tabel $(1,968)$ dan nilai signifikansi $0,000<0,005$, maka Ho ditolak dan Ha diterima. Artinya, secara parsial perceived ease of use memiliki pengaruh positif dan signifikan terhadap behavioral intention to use e-money. $\mathrm{t}$ hitung dari variabel perceived risk terhadap behavioral intention to use sebesar 8,474 dan nilai sig sebesar 0,000 . Dengan nilai t hitung $(8,474)$ $>\mathrm{t}$ tabel $(1,968)$ dan nilai signifikansi $0,000<0,005$, maka Ho ditolak dan Ha diterima. Artinya, secara parsial perceived risk memiliki pengaruh positif dan signifikan terhadap behavioral intention to use e-money.

\section{Koefisien Determinasi}

Tabel 9. Koefisien Determinasi

\begin{tabular}{|l|l|}
\hline $\mathbf{R}$ & R Square \\
\hline 0,834 & 0,710 \\
\hline
\end{tabular}

Sumber: Data yang telah diolah oleh peneliti, 2018

Tabel 9 menunjukkan nilai koefisien determinasi yang merupakan hasil kuadrat nilai $\mathrm{R}$ adalah sebesar 0,710 atau jika dalam bentuk persentase adalah sebesar $71 \%$. Hal tersebut menunjukkan bahwa sebesar $71 \%$ behavioral intention to use e-money dapat dijelaskan dengan menggunakan variabel perceived usefulness, perceived ease of use, dan perceived risk. Dan sebesar 29\% dijelaskan oleh faktor lain diluar penelitian ini.

\section{KESIMPULAN DAN SARAN \\ Kesimpulan}

Penelitian mengenai minat penggunaan e-money ini dilakukan kepada pengguna e-money di Universitas Telkom sebanyak 380 responden. Penelitian ini dilakukan 
dengan tujuan untuk faktor apa saja yang mempengaruhi minat penggunaan e-money, terutama pengaruh dari faktor perceived usefulness (X1), perceived ease of use (X2), dan perceived risk (X3) terhadap behavioral intention to use (Y) e-money. Setelah penelitian, pengolahan data, dan pengujian data selesai dilakukan, dapat disimpulkan bahwa:

1. Berdasarkan hasil pengujian secara parsial (Uji t), perceived usefulness (X1) memiliki pengaruh yang positif signifikan terhadap behavioral intention to use (Y) e-money.

2. Berdasarkan hasil pengujian secara parsial (Uji t), perceived ease of use (X2) memiliki pengaruh yang positif signifikan terhadap behavioral intention to use (Y) e-money.

3. Berdasarkan hasil pengujian secara parsial (Uji t), perceived risk (X3) memiliki pengaruh yang positif signifikan terhadap behavioral intention to use (Y) e-money.

4. Berdasarkan hasil pengujian secara simultan (Uji F), perceived usefulness (X1), perceived ease of use (X2) dan perceived risk (X3) memiliki pengaruh positif signifikan terhadap behavioral intention to use (Y) e-money. Dan berdasarkan hasil pengujian secara parsial (Uji t), perceived usefulness (X1) memiliki pengaruh positif dengan tingkat signifikan paling besar terhadap behavioral intention to use (Y) $e$ money.

\section{Saran}

\section{Berdasarkan Aspek Teoritis}

Penelitian selanjutnya dapat menggunakan model lain selain Technology Acceptance Model (TAM) seperti menggunakan UTAUT ataupun TPB, karena penggunaan model TAM pada penelitian ini sudah menunjukkan bahwa faktor perceived usefulness (X1), perceived ease of use (X2), dan perceived risk (X3) berpengaruh positif signifikan terhadap behavioral intention to use (Y) e-money.

Penelitian selanjutnya dapat menggunakan variabel lain diluar perceived usefulness, perceived ease of use, dan perceived risk. Hal ini berkaitan dengan hasil koefisien determinasi yang menunjukkan bahwa $29 \%$ behavioral intention to use emoney dijelaskan oleh faktor lain diluar perceived usefulness, perceived ease of use, dan perceived risk. Sebagai contoh, variabel lain yang bisa digunakan adalah trust, social image, dan influence.

\section{Berdasarkan Aspek Praktis}

Berdasarkan hasil uji hipotesis secara parsial (Uji t), faktor perceived usefulness (X1) yang memiliki pengaruh positif signifikan paling tinggi diantara faktor yang lain terhadap behavioral intention to use (Y) e-money. Dalam pernyataan analisa deskriptif, pertanyaan yang paling rendah yaitu pada item ketiga dengan pertanyaan penggunaan e-money lebih praktis karena tidak perlu membawa uang tunai. Oleh karena itu, disarankan pada perusahaan selaku produsen e-money dapat meyakinkan responden mengenai mudahnya penggunaan e-money karena tidak perlu repot membawa uang tunai dengan cara memberikan informasi lebih rinci mengenai manfaat dari penggunaan e-money.

Berdasarkan hasil uji hipotesis secara parsial (Uji t), faktor perceived ease of use (X2) yang memiliki pengaruh positif signifikan paling rendah diantara faktor 
yang lain terhadap behavioral intention to use (Y) e-money. Dalam pernyataan analisa deskriptif, pertanyaan yang paling rendah yaitu pada item kelima dengan pertanyaan e-money bisa di top-up dengan mudah dimana saja seperti ATM, bank, dan swalayan. Oleh karena itu, disarankan pada perusahaan selaku produsen $e$ money dapat memperluas sarana untuk top-up berbagai jenis e-money di setiap ATM, bank, dan swalayan, tidak hanya e-money tertentu saja.

Berdasarkan hasil uji hipotesis secara parsial (Uji t), faktor perceived risk (X3) yang memiliki pengaruh positif signifikan terhadap behavioral intention to use (Y) e-money. Dalam pernyataan analisa deskriptif, pertanyaan yang paling tinggi yaitu pada item ketiga dengan pertanyaan mengenai kekhawatir akan mendapatkan kerugian jika suatu saat sistem e-money mengalami kerusakan. Oleh karena itu, disarankan pada perusahaan selaku produsen e-money dapat memperbaiki sistem agar meminimalisir kerusakan dan meyakinkan responden bahwa sistem e-money tidak akan mengakibatkan kerugian apapun apabila terjadi kerusakan.

\section{DAFTAR PUSTAKA}

Arner, D. W., Barberis, J. N., \& Buckley, R. P. 2015. The Evolution of FinTech: A New Post-Crisis Paradigm? University of New South Wales Law Research Series.

Bank Indonesia. 2014. Peraturan Bank Indonesia Nomor 11 Tahun 2014 Tentang Uang Elektronik. Jakarta: Bank Indonesia.

Bank Indonesia. 2018. Statistik Sistem Pembayaran Transaksi Uang Elektronik. Retrieved September 18, 2018, from Bank Indonesia: https:/www.bi.go.id/id/statistik/sistem-pembayaran/uangelektronik/contents/transaksi.aspx

Gu, J., Lee, S., Suh, Y. 2009. Determinants of behavioral intention to mobile banking. Expert System with Application. 36 (9), 11605-11616.

Indrawati. 2015. Metode Penelitian Manajemen dan Bisnis Konvergensi Teknologi Komunikasi dan Informasi. Bandung: PT Refika Aditama.

Loanata, T., Tileng, K. G. 2016. Pengaruh Trust dan Perceived Risk pada Intention To Use Menggunakan Technology Acceptance Model (Studi Kasus Pada Situs ECommerce Traveloka). JUISI. 2 (1). 64-73.

Oentario, Y., Harianto, A., Irawati, J. 2017. Pengaruh Usefulness, Ease Of Use, Risk Terhadap Intentionto Buy Onlinepatisserie Melalui Consumer Attitude Berbasis Media Sosial Di Surabaya. Jurnal Manajemen pemasaran. 11 (1). 26-31.

Riek, M., Bohme, R, \& Moore, T. 2015. Measuring the Influence of Perceived.

Sanusi, A. 2011. Metode Penelitian Bisnis. Jakarta: Salemba Empat.

Sayekti, F., \& Putarta, P. 2016. Penerapan Technology Acceptance Model (TAM) dalam Pengujian Model Penerimaan Sistem Informasi Keuangan Daerah. Jurnal Manajemen Teori Terapan.

Sugiyono. 2018. Metode Penelitian Manajemen. Bandung: Alfabeta.

Sujarweni, V. W. 2015. Metodologi Penelitian Bisnis \& Ekonomi. Yogyakarta: Pustaka Baru Press.

Sukirno, Sadono. 2012. Makro Ekonomi: Teori Pengantar. Jakarta: Rajawali Pers.

Teo, T. 2011. Technology Acceptance in Education: Research and Issues. Netherlands: Sense Publishers. 
Waspada, I. 2012. Percepatan Adopsi Sistem Transaksi Teknologi Informasi untuk Meningkatkan Aksesibilitas Layanan Jasa Perbankan. Jurnal Keuangan dan Perbankan, 16, 122-131.

Wu, I.L., Li, J.Y. \& Fu, C.Y. 2011. The adoption of mobile healthcare by hospital's professionals: An integrative perspective. Decision Support Systems. 51 (3), 587596.

Yani, E., Lestari, A. F., Amalia, H., Puspita, A. 2018. Pengaruh Internet Banking Terhadap Minat Nasabah Dalam Bertransaksi Dengan Technology Acceptance Model. Jurnal Informatika. 5 (1). 34-42. 